\title{
Intracellular Patch Electrochemistry: Regulation of Cytosolic Catecholamines in Chromaffin Cells
}

\author{
Eugene V. Mosharov, ${ }^{1}$ Liang-Wei Gong, ${ }^{2}$ Bhavanna Khanna, ${ }^{2}$ David Sulzer, ${ }^{1}$ and Manfred Lindau ${ }^{2}$ \\ ${ }^{1}$ Departments of Neurology and Psychiatry, Columbia University, New York, New York 10032, Department of Neuroscience, New York State Psychiatric \\ Institute, New York, New York 10032, and '2 School of Applied and Engineering Physics, Cornell University, Ithaca, New York 14853
}

\begin{abstract}
Alterations in the cytosolic pool directly affect neurotransmitter synthesis and release and are suggested to be key factors in various neurodegenerative disorders. Although this cytosolic pool is the most metabolically active, it is miniscule compared with the amount of vesicular transmitter and has never been quantified separately. Here, we introduce intracellular patch electrochemistry (IPE), a technique that for the first time provides direct measurements of cytosolic oxidizable molecules in single mammalian cells. In amperometric mode, IPE detects total catechols, whereas in cyclic voltammetric mode, it preferentially measures catecholamines. In cultured chromaffin cells, the total cytosolic catechol concentration was $50-500 \mu \mathrm{M}$, of which $\sim 10 \%$ were catecholamines. Reserpine, a vesicular monoamine transporter inhibitor, had no effect on the catecholamine pool but increased total catechols by fourfold to fivefold. Combined with pargyline, a monoamine oxidase inhibitor, reserpine increased catecholamine levels in the cytosol by approximately sixfold. Amphetamine induced a transient approximately fivefold accumulation of cytosolic catecholamines and a slow increase of total catechols. In cells incubated with 3,4-dihydroxy-L-phenylalanine (L-DOPA), catecholamines increased by $\sim 2.5$-fold and total catechols increased by approximately fourfold. Cytosolic catecholamines returned to control levels $\leq 10 \mathrm{~min}$ after L-DOPA withdrawal, whereas total catechols remained approximately twofold elevated even after a $1.5 \mathrm{hr}$ incubation in L-DOPA-free media. Our data indicate that cytosolic catecholamines are strictly maintained at a defined level, and drug-induced increases in their concentrations lead to the accumulation of other catecholamine derivatives, such as DOPAC and 3,4-dihydroxyphenylethyleneglycol. These derivatives reside in the cytosol for hours after treatment and may be an underlying cause of drug-related cytotoxicity.
\end{abstract}

Key words: patch-amperometry; cyclic voltammetry; cytosolic catecholamine; chromaffin cells; reserpine; pargyline; amphetamine; L-DOPA

\section{Introduction}

The regulation of catecholamine metabolism in the cytosol has received much attention, because it has been shown that elevated catecholamines give rise to the formation of oxyradical species and catecholamine-protein adducts (Shen et al., 1996; Sulzer et al., 2000; Spencer et al., 2002). It has been suggested that abnormal catecholamine homeostasis may underlie the vulnerability of catecholaminergic neurons in various disorders including Parkinson's disease (Stokes et al., 1999; Conway et al., 2001; Shastry, 2001) and drug abuse (Lotharius and O'Malley, 2000; Davidson et al., 2001; Larsen et al., 2002). In contrast, pharmacological treatments that alter available cytosolic catecholamine also regulate the number of catecholamine molecules released per exocytic event (Colliver et al., 2000; Sulzer and Pothos, 2000), suggesting

\footnotetext{
Received Feb. 11, 2003; revised April 17, 2003; accepted April 21, 2003.

This work was supported by National Institute on Drug Abuse Grant 10154 (D.S.), National Institute of Neurological Disorders and Stroke Grant 38370 (D.S.), Parkinson's Disease Foundation (D.S.), National Institutes of Health Grant R01NS38200 (M.L.), and the Nanobiotechnology Center (M.L.) (National Science Foundation Science and Technology (enters agreement ECS-9876771).We thank Drs. Ismail Hafez and Ryan Nelson for the confocal imaging of chromaffin cells, Drs. Lori Kwan, Joan Lenz, and Roland Staal for chromaffin cell preparation and excellent technical assistance, and Drs. Yvonne Schmitz, Dmitriy Markov, and Kristin Larsen for critique of this manuscript.

Correspondence should be addressed to David Sulzer, BB 305, 650 W 168th Street, New York, NY 10032. E-mail: ds43@columbia.edu.

Copyright $\odot 2003$ Society for Neuroscience $\quad 0270-6474 / 03 / 235835-11 \$ 15.00 / 0$
}

that free catecholamine levels may play a role in synaptic plasticity. To understand mechanisms underlying dopamine (DA) neurotoxicity and the regulation of catecholamine secretion, it is crucial to understand the principles of catecholamine homeostasis in the cytosol.

Cytosolic catecholamines, which are believed to constitute only a small fraction of the total intracellular catecholamine content, have never been directly determined in mammalian cells. The development of electrochemical detection methods (Kissinger et al., 1973) and the introduction of the carbon fiber microelectrode (CFE) (Gonon et al., 1978; Ponchon et al., 1979) have provided a means to measure concentrations of a variety of oxidizable metabolites, including catecholamines. CFEs in amperometric (constant voltage) and cyclic voltammetric (CV; voltage ramps) modes have been extensively used to study the mechanisms of dopamine and norepinephrine exocytic release in different cell types (Wightman et al., 1991; Bruns and Jahn, 1995; Chen et al., 1995; Jaffe et al., 1998; Pothos et al., 1998). However, these methods provided little or no information about the regulation of the cytosolic pool of neurotransmitter. The first attempt to directly measure catecholamines in the cytoplasm was made by Chien et al. (1990) and Olefirowicz and Ewing (1990). Because of the large size of the giant dopamine neuron (GDN) of the pond snail, it was possible to insert the CFE directly in the neuronal cell 
body or perform a capillary electrophoresis of its intracellular metabolites. Another approach, which used an amperometric detection of catecholamines released from digitoninpermeabilazed chromaffin cells, was used to study comparative changes in cytosolic catecholamines induced by different weak bases (Mundorf et al., 1999) but did not provide information about the absolute metabolite concentrations.

The recently introduced technique of cell-attached patch amperometry combines patch-clamp recordings of cell membrane capacitance and conductance with amperometric detection of released catecholamines using a CFE located inside a patch pipette. Patch amperometry has made simultaneous measurement of vesicle volume and the amount of catecholamine secreted from the same vesicle possible (Albillos et al., 1997). We combined patch-amperometric recording in the whole-cell configuration with amperometric and CV detection of catecholamines within the cytosol of individual cells. Data obtained with this approach provide answers to longstanding questions about the mechanisms of cytosolic catecholamine regulation.

\section{Materials and Methods}

Chemicals were purchased from Sigma (Milwaukee, WI) unless otherwise stated. All stock solutions were prepared at $10 \mathrm{~mm}$ concentration. Reserpine and calcein-AM (Molecular Probes, Eugene, OR) were diluted in DMSO, amphetamine in EtOH, and 3,4-dihydroxy-L-phenylalanine (L-DOPA) in $0.1 \mathrm{~N} \mathrm{HCl}$. Corresponding solvents were added to control cultures. Animal protocols were approved by the Columbia University and Cornell University Institutional Animal Care and Use Committees.

Primary adrenal chromaffin cell cultures. Bovine chromaffin cells were prepared and cultured as described previously (Parsons et al., 1995). For rat-derived cultures, adrenal glands from 2- to 7-d-old Sprague Dawley rats were dissected in ice-cold HBSS. The capsule and cortex of adrenal glands were removed and the remaining medullae were minced. After several washes with HBSS, the tissue was incubated with $\mathrm{Ca}^{2+}$-free collagenase IA solution $(250 \mathrm{U} / \mathrm{ml})$ for $30 \mathrm{~min}$ at $30^{\circ} \mathrm{C}$ with stirring. The digested tissue was rinsed three times with HBSS and triturated gently in a solution containing $1 \%$ heat-inactivated bovine serum albumin and $0.02 \%$ DNase I. Dissociated cells were centrifuged at $3000 \mathrm{rpm}$ to form a pellet and then resuspended in a culture medium comprised of DMEM, $10 \%$ fetal bovine serum, $50 \mathrm{U} / \mathrm{ml}$ penicillin, and $50 \mu \mathrm{g} / \mathrm{ml}$ of streptomycin. The cell suspension was plated onto poly-D-lysine and laminincoated glass wells in $50 \mathrm{~mm}$ dishes and, after 1-2 hr, the dishes were flooded with the culture medium. Cells were maintained in a $7 \% \mathrm{CO}_{2}$ incubator at $37^{\circ} \mathrm{C}$. All measurements were conducted between 1 and 7 post-plating days.

Solutions. Solutions used for amperometric recordings from bovine chromaffin cells were as follows. The bath saline Al contained the following (in mM): $140 \mathrm{NaCl}, 5 \mathrm{KCl}, 2 \mathrm{MgCl}_{2}, 5 \mathrm{CaCl}_{2}, 10$ glucose, 10 HEPES-NaOH, pH 7.2. Pipette extracellular saline A2 contained the following (in mM): $50 \mathrm{NaCl}, 100$ TEA-Cl, $5 \mathrm{KCl}, 10 \mathrm{CaCl}_{2}, 1 \mathrm{MgCl}_{2}, 10$ HEPES-NaOH, pH 7.3. Pipette intracellular saline A3 contained the following (in mM): $145 \mathrm{CsGlu}, 8 \mathrm{NaCl}, 2 \mathrm{MgCl}_{2}, 2 \mathrm{ATP}, 0.3 \mathrm{GTP}, 10$ HEPES-NaOH, pH 7.3.

For amperometric and CV recordings from rat chromaffin cells, the bath saline $\mathrm{B} 1$ contained the following (in $\mathrm{mm}$ ): $128 \mathrm{NaCl}, 2 \mathrm{KCl}, 2$ $\mathrm{MgCl} 2,1.2 \mathrm{CaCl} 2,1 \mathrm{NaH}_{2} \mathrm{PO}_{4}, 10$ glucose, 10 HEPES-NaOH, pH 7.2. The same solution was used as an extracellular pipette solution. Intracellular pipette saline B2 contained the following (in mM): $140 \mathrm{KGlu}, 2$ $\mathrm{MgCl}_{2}, 0.1 \mathrm{CaCl}_{2}, 1$ EGTA, 10 HEPES, 2 ATP, 0.1 GTP, pH 7.3. During $\mathrm{CV}$ recordings from L-DOPA-treated cells, $100 \mu \mathrm{M} \mathrm{L}$-DOPA was added to the bath and the pipette solution.

Electrochemical setup. Electrode holders were adapted from those used for patch amperometry (Albillos et al., 1997). The holder contained two $\mathrm{Ag} \mid \mathrm{AgCl}$ electrodes. One was attached to the ground in contact with the pipette solution. The other, which provided current for the CFE via $3 \mathrm{~m}$ $\mathrm{KCl}$ solution in polyethylene tubing, was connected to the input of a homemade or Axopatch 200B (Axon Instruments, Union City, CA) am- plifier. This electrode pair was used for electrochemical detection of metabolites diffusing from the cytosol into the patch pipette. Constant voltage (amperometry) or voltage ramps (CV) were applied to the CFE using PCI-6052E (National Instruments, Austin, TX) or ITC-18 (InstruTech, Port Washington, NY) analog-to-digital converter. Because the ground electrode was inside the patch pipette, an $\mathrm{Ag} \mid \mathrm{AgCl}$ electrode connected to the input of another Axopatch 200B amplifier was in contact with a bath saline (see Fig. 1A). Square or sine wave voltage signals were applied to this electrode to measure seal formation and patch disruption and monitor changes in access resistance (Lindau and Neher, 1988; Thompson et al., 2001).

We found that in CV mode of detection, the output current was affected by suction pulses applied to the patch pipette. For CV measurements, the design of the electrode holder was therefore changed to isolate the compartment inside the polyethylene tubing from the patch pipette compartment (see Fig. $1 \mathrm{~B}$ ). Recording pipettes (borosilicate glass; wall thickness, $0.3 \mathrm{~mm}$; outer diameter, $2 \mathrm{~mm}$ ) were pulled with a micropipette puller (Model P-97; Sutter Instruments, Novato, CA) and fire polished before use. The typical pipette resistance in the bath was $1.5-5 \mathrm{M} \Omega$.

Amperometry. For the amperometric mode of intracellular patch electrochemistry (IPE), the CFE potential was held at $700 \mathrm{mV}$. When the plasma membrane was ruptured by suction, substances diffusing from the cytosol into the patch pipette were observed as a slow wave of oxidation current. After baseline subtraction, the total area, the charge $(Q)$, of this oxidation current wave was used to estimate cytosolic catecholamine concentration $(C)$ using the following formula:

$$
C=\frac{Q}{n \cdot F \cdot V}
$$

where $n$ is the number of electrons transferred from a molecule to the CFE, which was assumed to equal two (Baur et al., 1988); F is Faraday's constant, and $V$ is the cytosolic volume.

Cyclic voltammetry. Data acquisition and analysis for IPE in CV mode were performed using a subroutine locally written in Igor Pro (WaveMetrics, Lake Oswego, OR). All programs used in the present study can be downloaded from our laboratory website (http://www.columbia.edu/ $\sim$ ds43/download.html). Voltage ramps, from $-450 \mathrm{mV}$ holding potential to $800 \mathrm{mV}$ and then back to $-450 \mathrm{mV}$ over $10 \mathrm{msec}$ (scan rate, 250 $\mathrm{mV} / \mathrm{msec}$ ), were applied at $90 \mathrm{msec}$ intervals.

Volume calculations. Cytosolic volume and the volume inside the patch pipette that contributed to the dilution of molecules (see Results) were estimated from photographs taken before each recording (see Fig. $2 A, B$ ). The corresponding volumes were then calculated as (see Fig. $2 B$ for parameters description):

$$
V_{\text {cell }}=S \cdot \frac{4}{3} \pi \cdot R_{\text {cell }}^{3} \text {, and } V_{\text {pipette }}=\pi \frac{h}{3} \cdot\left(R_{a}^{2}+R_{b}^{2}+R_{a} \cdot R_{b}\right) \text {, }
$$

where $h=h_{\text {vis }} \cdot \sqrt{2}$. Cultured bovine chromaffin cells were generally spherical, as shown in a three-dimensional reconstruction of a cell incubated for $15 \mathrm{~min}$ in solution A1 containing $100 \mu \mathrm{M}$ calcein-AM and imaged using confocal microscopy (see Fig. 2C). However, some cells in rat chromaffin culture appeared somewhat flattened, in which case the volume estimate was reduced by a factor $S$ to account for shape distortion. The coefficient $S$ was $0.5,0.75$, or 1 depending on the shape of the cell under the microscope.

Calibration measurements. Amperometric calibration measurements for all concentrations of each compound were performed in triplicate with the same CFE and reference electrodes. CV calibrations obtained using different CFEs were normalized to the same electrode sensitivity (see Results). Current readings were taken 30-60 sec after the addition of compounds when the current was stable.

Statistical analysis. One-way ANOVA tests between different treatment groups were performed using Microsoft Excel program (Microsoft, Seattle, WA). 


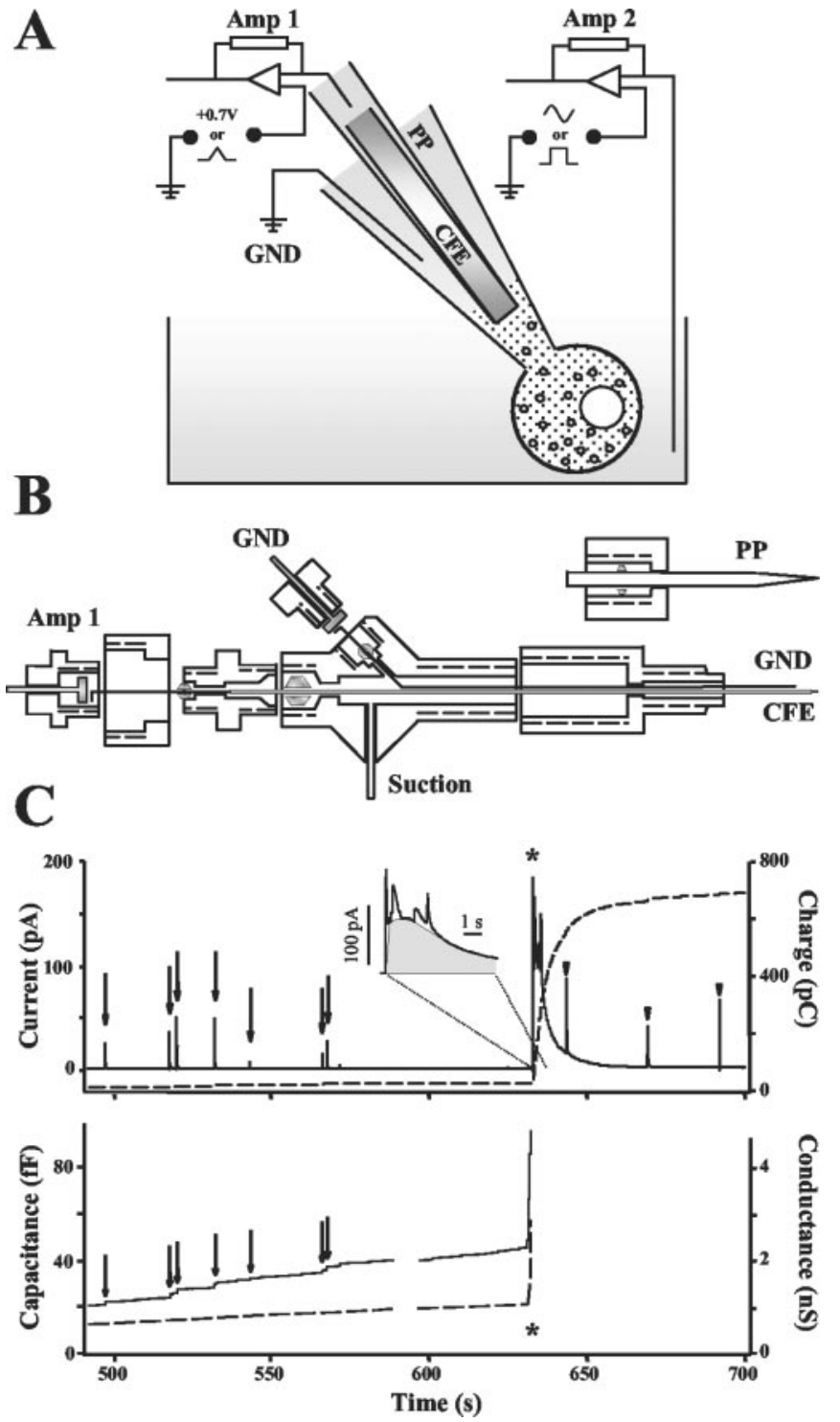

Figure 1. A, Schematic diagram of the IPE setup. Amp 1, Amp 2, Amplifiers; GND, electric ground; $C F E$, carbon fiber electrode; PP, patch pipette. $B$, Design of the IPE electrode holder. Two $\mathrm{Ag} \mid \mathrm{AgCl}$ wires are connected to the GND and Amp 1 via golden-plated pins. The ground wire is in contact with the PP saline; an electrode wire supplies electric current to the CFE via polyethylene tubing filled with $3 \mathrm{M} \mathrm{KCl}$. Air tightness between different compartments inside the holder is achieved by four rubber 0 -rings. $C$, An amperometric recording from a bovine chromaffin cell in which measurement of quantal release of catecholamines by patch amperometry is followed by IPE in amperometric mode. Asterisks indicate the time when the patch was disrupted by suction and a whole-cell configuration was attained. Amperometric current from the CFE (top, solid line), its running integral (top, dashed line), membrane capacitance (bottom, solid line), and conductance (bottom, dashed line) were monitored simultaneously during the same recording. Quantal events in the patch are indicated by amperometric spikes and capacitance steps (arrows). In $\sim 50 \%$ of the recordings, the slow amperometric current wave had superimposed quantal spikes, indicating vesicles diffusing out of the cell and bursting on contact with the CFE (arrowheads). The inset displays a magnification of the initial phase of the slow oxidation wave. The first sharp peak from the left is an artifact resulting from suction. The gray area shows the portion of the peak considered to represent the cytosolic molecules.

\section{Results}

\section{IPE in amperometric mode}

Cell-attached patch amperometry uses a CFE and an $\mathrm{Ag} \mid \mathrm{AgCl}$ reference electrode. Both are located inside a patch pipette (Fig. $1 A, B)$ to simultaneously measure quantal release of catecholamines in a cell-attached configuration and capacitance steps reflecting exocytosis of single vesicles. The capacitance is determined by applying a sine wave voltage between an additional electrode in the bath and the same reference electrode in the patch pipette, measuring the resulting current, and analyzing it with a lock-in amplifier (Albillos et al., 1997). Amperometric spikes and associated capacitance steps indicate exocytosis of individual vesicles (Fig. 1C, solid lines, arrows). The volume of each vesicle can be calculated from the vesicle capacitance, and the amount of catecholamine in the same vesicle is obtained by integrating the corresponding amperometric spike (Fig. 1C, top, dashed line), providing simultaneous measurements of quantal size, vesicle size, and vesicular catecholamine concentration (Albillos et al., 1997).

Cytosolic catecholamine concentrations can be determined using the same principles. When the patch was disrupted by a strong suction pulse, capacitance increased to an off-scale value as the whole-cell configuration was attained (Fig. 1C, asterisks). This allowed catecholamines to diffuse from the cytosol into the pipette, and a slow wave of oxidation current was measured by the CFE inside the patch pipette (Fig. 1C, top, solid line). In $\sim 50 \%$ of the recordings, amperometric spikes similar to those observed for exocytic events were seen superimposed on this slow wave (Fig. $1 C$, arrowheads). These spikes presumably represented vesicles that diffused into the pipette and burst as they encountered the surface of the CFE. After appropriate baseline subtraction, the slow current wave was integrated (Fig. $1 C$, top, dashed line), and the amount of oxidizable molecules in the cytosol was estimated (see Materials and Methods). Superimposed amperometric events from bursting vesicles were subtracted to obtain the contribution solely from the cytosol (Fig. 1C, inset). The example shown in Figure $1 C$ yielded a charge of $\sim 611$ pC, corresponding to $3.2 \mathrm{fmol}$ catechols. The diameter of this cell calculated from its photograph was $20 \mu \mathrm{m}$, providing a cellular volume of $4.2 \mathrm{pl}$ (Fig. $2 A, B$ ) and a cytosolic catechol concentration of $\sim 700 \mu \mathrm{M}$.

\section{Calibrations}

The wave of oxidation current detected by amperometry represents all cytosolic oxidizable molecules. To determine the response of a CFE at $700 \mathrm{mV}$ to various metabolites, the following compounds were tested: the catecholamines DA, norepinephrine (NE), and epinephrine (EP), their precursor L-DOPA, the catecholamine degradation products 3,4-dihydroxyphenylethyleneglycol (DOPEG), 3,4-dihydroxyphenylacetate (DOPAC), homovanillic acid (HVA), and ascorbic acid (AA). Calibration curves for these compounds plotted in double logarithmic coordinates were all linear with slopes in the range of $0.6-0.73$ and yielded similar amperometric currents at any given metabolite concentration (Fig. 2D, Table 1). Therefore, IPE in amperometric mode measures all oxidizable molecules in the cytosol, including all catechol derivatives and AA, with similar sensitivity.

\section{IPE in CV mode}

In contrast to constant voltage amperometry, $\mathrm{CV}$ differentiates between various metabolites on the basis of their redox properties. Catecholamines have specific oxidation-reduction profiles (voltammograms) with an oxidation peak at $350-450 \mathrm{mV}$ for the voltage scan rate used here (Chow and von Ruden, 1995). We used IPE in CV mode to determine cytosolic catecholamines more exclusively. The current resulting from voltage ramps (see Materials and Methods) was recorded as a three-dimentional matrix of data (Fig. $3 A$ ). Current near the maximum of the catecholamine oxidation potential was sampled (Fig. 3 C, indicated by 


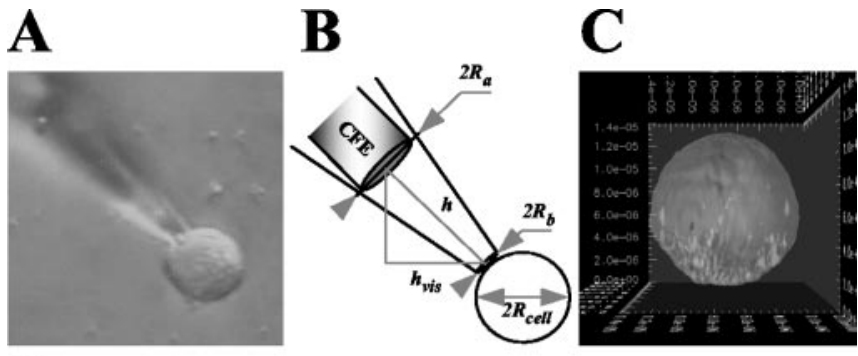

D
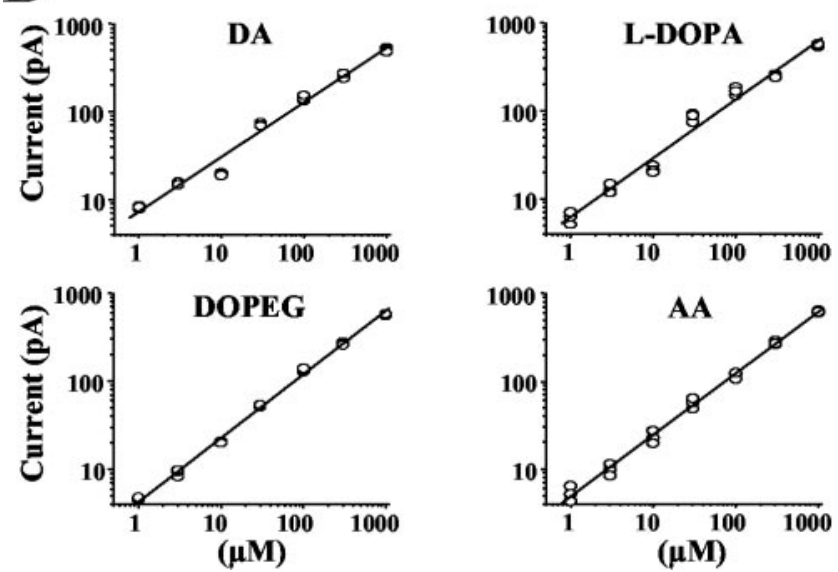

Figure 2. A, An example of a photograph obtained before each recording and used to calculate the dilution of molecules inside the patch pipette (see Materials and Methods). B, Estimation of the cytosolic volume, $V_{\text {cell }}$, and the volume inside the patch pipette, $V_{\text {pipette }}$ that contributed to the dilution of intracellular content. $C, A$ three-dimensional reconstruction of a calcein-AM-stained bovine chromaffin cell scanned by confocal microscopy. $D$, Concentration dependence of amperometric currents for DA, L-DOPA, DOPEG, and ascorbic acid in double logarithmic plots fit by linear functions. Calibration coefficients for these and other compounds are listed in Table 1.

the red line in $A$ ) to determine the time corresponding to the maximal catecholamine concentration at the CFE. When present, baseline drifts on the sampled current trace were removed by subtracting the current sampled at $0 \mathrm{mV}$ (Fig. $3 A$, blue line). Voltammograms of substances released from cells (Fig. $3 B$ ) were obtained by subtracting voltage-current sections of the threedimensional data matrix measured at a time before patch rupture (an average of 10 consecutive sections at any time preceding the $30 \mathrm{sec}$ time point) (Fig. 3) from those at the maximum of catecholamine oxidation wave (an average of 10 sections at $\sim 33 \mathrm{sec}$ ). Catecholamine concentrations were calculated from the height of their oxidation peaks $(\Delta I)$ on the voltammogram (Fig. $3 B$ ). Pseudo-three-dimensional reconstructions of changes in the voltammograms during the recordings were used to estimate the time course of catecholamine release from cells (Fig. 3D).

\section{Calibrations}

Substances listed in Table 1 were calibrated using CFEs in CV mode. In agreement with previous reports (Wiedemann et al., 1990; Pihel et al., 1996), CV was differentially sensitive to various catechol metabolites. At the same concentrations, DA, EP, and NE yielded 10-20 times higher oxidation peaks than DOPAC, DOPEG, HVA, vanillylmandelic acid, or L-DOPA (Fig. 4A, Table 1).

The concentration dependence of DA oxidation peak $(\Delta I)$ varied for individual CFEs (Fig. $4 B$ ), presumably reflecting differences in the active electrode area. Nevertheless, $\Delta I$ was proportional to the background current sampled at the same voltage $\left(I_{B}\right)$ (Fig. 3C) for any given concentration of DA, indicating that $I_{B}$
Table 1. Sensitivity of CFEs in amperometric and CV modes to different metabolic compounds

\begin{tabular}{lllll}
\hline Compound & $A^{a}$ & $B^{a}$ & $\Delta /$ at $10 \mu \mathrm{m}^{b}$ & Ratio $^{c}$ \\
\hline Amperometry & & & & \\
DA & $0.86 \pm 0.02$ & $0.62 \pm 0.04$ & 30 & 1 \\
NE & $0.89 \pm 0.02$ & $0.61 \pm 0.03$ & 32 & 1 \\
EP & $0.85 \pm 0.01$ & $0.6 \pm 0.02$ & 28 & 1.1 \\
I-DOPA & $0.8 \pm 0.01$ & $0.67 \pm 0.02$ & 30 & 1 \\
DOPEG & $0.62 \pm 0.02$ & $0.73 \pm 0.04$ & 22 & 1.3 \\
DOPAC & $0.7 \pm 0.02$ & $0.68 \pm 0.04$ & 24 & 1.3 \\
HVA & $0.74 \pm 0.01$ & $0.64 \pm 0.02$ & 24 & 1.3 \\
AA & $0.69 \pm 0.01$ & $0.7 \pm 0.02$ & 25 & 1.2 \\
CV & & & & \\
DA & $2.71 \pm 0.03$ & $0.72 \pm 0.04$ & 2690 & 1 \\
NE & $2.39 \pm 0.08$ & $0.81 \pm 0.07$ & 1580 & 1.7 \\
EP & $2.21 \pm 0.28$ & $0.8 \pm 0.27$ & 1030 & 2.6 \\
I-DOPA & $1.64 \pm 0.13$ & $0.77 \pm 0.09$ & 250 & 10.8 \\
DOPEG & $1.64 \pm 0.13$ & $0.89 \pm 0.1$ & 340 & 7.9 \\
DOPAC & $1.31 \pm 0.25$ & $0.84 \pm 0.16$ & 140 & 19.2 \\
HVA & $1.54 \pm 0.2$ & $0.85 \pm 0.15$ & 240 & 11.2 \\
VMA & $1.69 \pm 0.11$ & $0.5 \pm 0.07$ & 150 & 17.9 \\
AA & $0.95 \pm 0.15$ & $0.79 \pm 0.06$ & 50 & 53.8 \\
\hline
\end{tabular}

${ }^{a}$ Calibration coefficients were derived from the linear fit, $\log (\Delta)=A+B^{*} \log (Q$, where $\Delta /$ is in picoamperes and $C$ is in micrometers. Examples of the calibration curves are shown in Figures $2 D$ and $4 D$. For CV calibrations, the reference background current, $I_{S}$ std, was set at $30 \mathrm{nA}$. The coefficients are shown with the experimental errors.

${ }^{b}$ Current was calculated using the formula, $\Delta I_{C}=10^{\wedge}\left[A+B^{*} \log (C)\right]$, where $\Delta I_{C}(\mathrm{pA})$ is an oxidative current at $C$ $(\mu \mathrm{m})$ concentration of a compound. For CV calibrations, $\Delta I_{\text {norm }}$ values are presented (see Results).

' Ratio was calculated between $\Delta /$ at $10 \mu \mathrm{m}$ for DA and other compounds.

had an identical dependence on the electrode surface (Fig. 4C). $I_{B}$ was therefore used to normalize the responses of the individual electrodes as follows:

$$
\Delta I_{\text {norm }}=\Delta I \cdot I_{B}^{\mathrm{std}} / I_{B}
$$

where $\Delta I_{\text {norm }}$ is the normalized height of the catecholamine oxidation peak, and $I_{B}^{S t d}$ is the reference background current.

To convert $\Delta I_{\text {norm }}$ into a concentration, calibration measurements were performed over a wide range of DA (Fig. 4D) and other compounds levels (Table 1). Similar to amperometric calibrations, the data points for $\mathrm{CV}$ calibration curves were well fit by a linear function in double logarithmic coordinates. Metabolite concentration $(C)$ may thus be obtained using the following formula:

$$
C=10\left(-\frac{A}{B}\right) \cdot \Delta I_{\text {norm }}^{\left(\frac{1}{B}\right)}
$$

where $\Delta I_{\text {norm }}$ is in $\mathrm{pA}, C$ is in $\mu \mathrm{M}$, and $A$ and $B$ are the calibration coefficients from Table 1 .

\section{Dilution of molecules}

As IPE in CV mode detects catecholamine concentration at the tip of the CFE, which is a few micrometers away from the cell, it was necessary to account for the dilution of molecules inside the patch pipette. We used two approaches to estimate the initial cytosolic catecholamine concentration. First, in the "geometric" approach, cellular volume and the volume of the patch pipette, from its tip to the tip of the CFE, were estimated from photographs taken before each recording (see Materials and Methods) (Fig. $2 A, B$ ), and the concentration of catecholamines at the CFE was multiplied by the calculated dilution factor, $\left(V_{\text {cell }}+V_{\text {pipette }}\right) /$ $V_{\text {cell }}$. However, this method underestimated the true cytosolic catecholamine concentrations for two reasons: (1) there was a loss of molecules from the diffusion of catecholamines around the CFE into the shaft of the pipette, and (2) the actual free volume of the cytosol might be smaller than the total cell volume, 
A

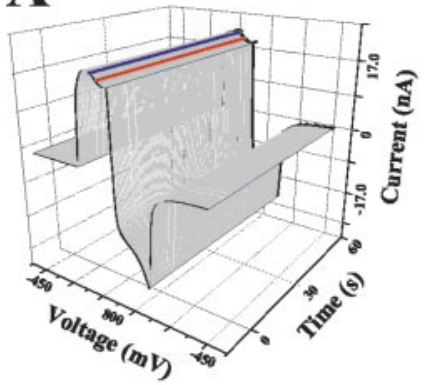

B
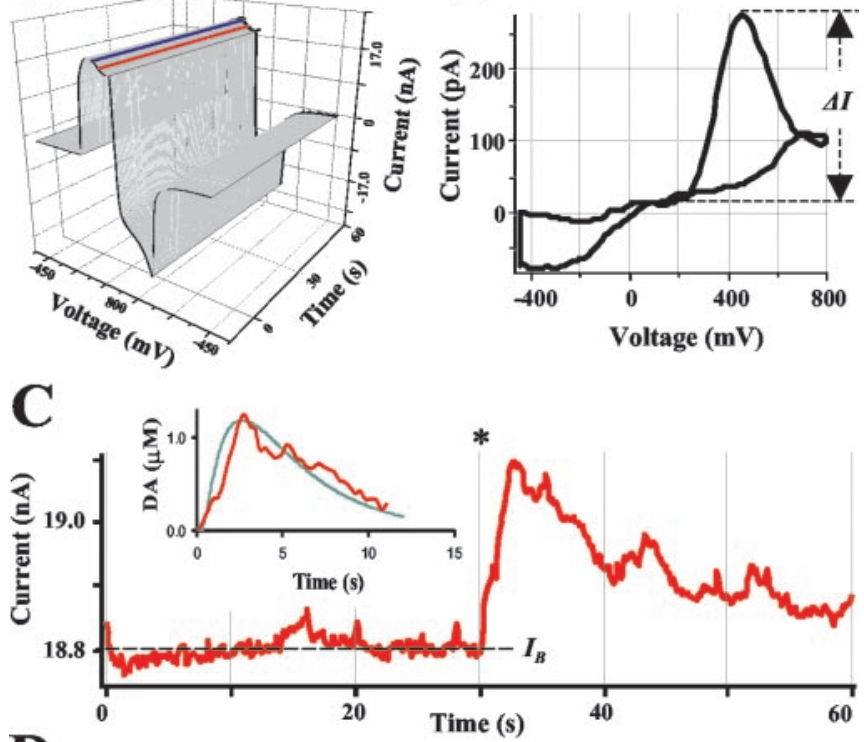

D

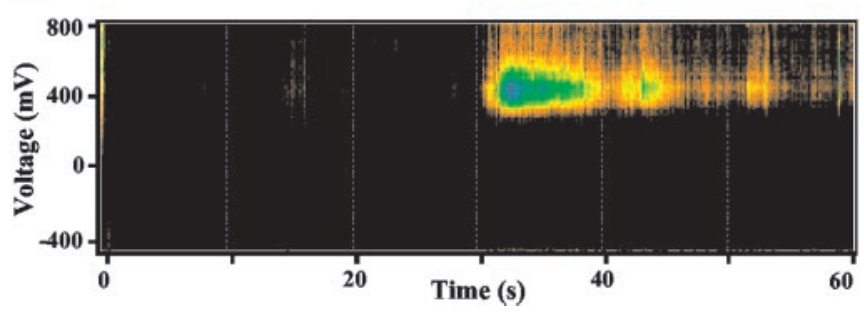

Figure 3. Analysis of $C V$ recordings from a single rat chromaffin cell. $A, A$ representative recording shown as a three-dimentional matrix of data. Red and blue lines represent samplings of the current at 400 and $0 \mathrm{mV}$, respectively. $B$, Voltammogram of catecholamines released during the same recording. A subtraction was made between 10 consecutive averaged $I-V$ profiles at $10 \mathrm{sec}$ from those at $33 \mathrm{sec}$. Dashed line indicates $\Delta /$, the height of DA oxidation peak. C, Current sampled at $400 \mathrm{mV}$ oxidation potential. The asterisk indicates a time when the patch was disrupted by suction and a whole-cell configuration was attained. The inset shows a random walk fit (green) of the sampled current trace (red) using $15 \mathrm{M} \Omega$ access resistance, $8 \mu \mathrm{m}$ cell radius, $60 \mu \mathrm{m}$ distance between the CFE and the pipette tip, and $6.7 \mu \mathrm{m}$ cytosolic catecholamine concentration. $D$, Pseudo-three-dimensional representation of approximate voltammograms of intracellular metabolites encountering the CFE during the recording, in which the intensity of color ("Planet Earth" color table) indicates the current at a given voltage and time. The algorithm used to calculate catecholamine concentration in this recording is discussed in Results.

because a portion of the cytosol is occupied by vesicles and other organelles.

The second approach used a random walk (RW) simulation (Berg, 1983; Sulzer and Pothos, 2000) to fit experimentally recorded sampled current traces and calculate the initial concentration of catecholamines inside the cell. The RW simulation, which was written in Excel (Microsoft), was based on two functions: diffusion of catecholamines from a spherical source of molecules through a small pore, and diffusion of molecules outside the cell from the pipette tip to the CFE. The first function was measured by Pusch and Neher (1988) and takes into account cell diameter, diffusion coefficient of catecholamines $(D=6.9 \times$ $10^{-6} \mathrm{~cm}^{2} / \mathrm{sec}$ ) (Nicholson, 1999), and the access resistance of the patch pipette, which is a measure of the pore size at the pipette tip through which molecules diffuse from the cell into the pipette (Pusch and Neher, 1988). The second function describes the diffusion of catecholamines from a point source of molecules (the tip of the patch pipette) to the CFE. The initial intracellular con- centration of catecholamines inside the cell was varied until the best fit of the experimental data was obtained. However, a weakness of this model is that it does not account for the restriction of diffusion by the pipette walls, thus, overestimating cytosolic catecholamine concentrations.

In the example of a single cell recording shown in Figure 3, the height of the oxidation peak determined from the voltammogram (Fig. $3 B$ ) taken at the maximum of the catecholamine oxidation wave was $\Delta I=377 \mathrm{pA}$, and the background current $I_{B}$ was $18.8 \mathrm{nA}$. These currents then yielded $\Delta I_{\text {norm }}=602 \mathrm{pA}$ from Equation 1 and a catecholamine concentration at the CFE of 1.25 $\mu \mathrm{M}$ from Equation 2. The dilution factor calculated from cell and pipette geometric parameters was 2.9, yielding an estimate of 3.6 $\mu \mathrm{M}$ catecholamines in the cytosol. The RW best fit of the oxidation current wave (Fig. $3 C$, inset) yielded a $6.7 \mu \mathrm{M}$ cytosolic catecholamine concentration. On average, the geometric method produced an estimate of cytosolic catecholamines $2.3 \pm 0.6$-fold lower than the RW simulation (mean $\pm \mathrm{SD} ; n=9$ ). Because the first method provided a lower estimate and the second method a provided a higher estimate of the cytosolic levels of catecholamines, for the data presented below, an average of the two methods was approximated as follows: the catecholamine concentrations were calculated using the simpler geometric method and then multiplied by the factor of 1.65 , derived from $(2.3+1) / 2$.

\section{Subtraction of $A A$}

Although CV was $\sim 50$-fold more sensitive to catecholamines than to ascorbic acid (Table 1), it was necessary to account for the contribution of AA to the oxidation current, because it may reach high intracellular levels in chromaffin cells (Ingebretsen et al., 1980; Levine et al., 1985). On the basis of the markedly different shape of the AA voltammogram, an algorithm was developed to detect and subtract its contribution to the measured catecholamine voltammograms, as illustrated in Figure $4 \mathrm{E}$. In this example, AA was added at $400 \mu \mathrm{M}$ concentration followed by the addition of $5 \mu \mathrm{M}$ EP. From -350 to 0 $\mathrm{mV}$, the ascorbate voltammogram showed a pronounced slope, whereas catecholamine voltammograms were essentially flat (Fig. $4 E$, bottom, left). The AA concentration was thus estimated from this slope on the voltammograms. The complete AA voltammogram was then approximated by three lines (bottom, middle, dashed line). This basic shape was assumed to be invariant, but the amplitude of its contribution was scaled in proportion to the measured slope between -350 and $0 \mathrm{mV}$. The approximate scaled version of the AA voltammogram was then subtracted. The resulting difference closely reproduced the original voltammogram of EP (Fig. $4 E$, compare solid lines in left and right bottom panels).

Nearly one-half of rat chromaffin cells (90 of 190 cells) exhibited a slope between -350 and $0 \mathrm{mV}$ with the average $\Delta I$ current of $1550 \mathrm{pA}$. Using AA calibration coefficients (Table 1), this corresponded to $700 \pm 83 \mu \mathrm{M}$ ascorbate (mean \pm SEM; $n=90$ ), although AA might not be the only factor that contributed to this oxidative current. For example, contributions from L-DOPA would also be partially subtracted because of the particular shape of its voltammogram (Fig. $4 A$ ). It should be noted also that in the amperometric mode of detection, the concentrations of catechols may be overestimated because of the presence of AA. These and other factors that may introduce uncertainties and cumulative errors in amperometric and CV measurements of catechol concentrations are summarized in Discussion. 
Catecholamine levels in untreated chromaffin cells

Cytosolic levels of oxidizable metabolites in untreated chromaffin cells measured by both amperometry and CV decreased with time in culture with a decay time constant of 3-4 d (Fig. 5A). Histograms of amperometrically detected compounds measured on day 1, days 2-4, and days 5-7 showed that the distributions from the younger cultures contained many cells with very high catechol concentrations (Fig. 5B). Distributions obtained on days 2-4 from bovine (Fig. $5 B$, middle) and rat (Fig. $5 C$, right) chromaffin cells had identical mean values of $290 \pm 27 \mu \mathrm{M}(n=98)$ and $290 \pm$ $21 \mu \mathrm{M}(n=97)$, respectively (mean \pm SEM).

On day 1 after plating, the average concentration of oxidizable metabolites measured by amperometry was $\sim 500 \mu \mathrm{M}$, whereas the catecholamine level estimated by $\mathrm{CV}$ was $\sim 50 \mu \mathrm{M}$. This $10: 1$ ratio between amperometric and CV measurements remained almost unchanged over subsequent days (Fig. 5A). As discussed previously, amperometry is similarly sensitive to all tested metabolites, whereas CV is several-fold more sensitive to catecholamines DA, NE, and EP than to L-DOPA, DOPAC, or DOPEG (Table 1). Therefore, this is consistent with a 10:1 ratio between total catechol and catecholamine concentrations.

To minimize the influence of cell-tocell variability, for additional experiments, we used cells that were cultured for 2-4 d when the relatively high concentrations of catechols were distributed with a minimal occurrence of outliers (Fig. $5 C$, right). The cytosolic concentration of catecholamines in rat adrenal cells at this time point was $21.5 \pm 2 \mu \mathrm{M}($ mean $\pm \mathrm{SEM} ; n=90)$, with $>80 \%$ of the cells containing 5-35 $\mu \mathrm{M}$ catecholamines (Fig. $5 C$, left). Each group of recordings from drug-treated cells (see below) was matched with the control group from the same culture batch that was recorded the same day.

Measurements performed in extracellular and low-calcium intracellular patch pipette solutions yielded the same catechol levels in both amperometric (saline A2 and A3) and CV (saline B1 and B2; see Materials and Methods for compositions) modes (Fig. 5D). No changes in cytosolic catecholamine homeostasis were observed during 1.5-2 hr of cell incubation in the recording solution (data not shown). No correlation was found between cytosolic volume and the concentrations of cytosolic catechols or catecholamines (data not shown).

Perturbations of cytosolic catecholamine homeostasis in drug-treated cells

Several pharmacological treatments have been suggested to alter intracellular catecholamine pools distribution in neurons and
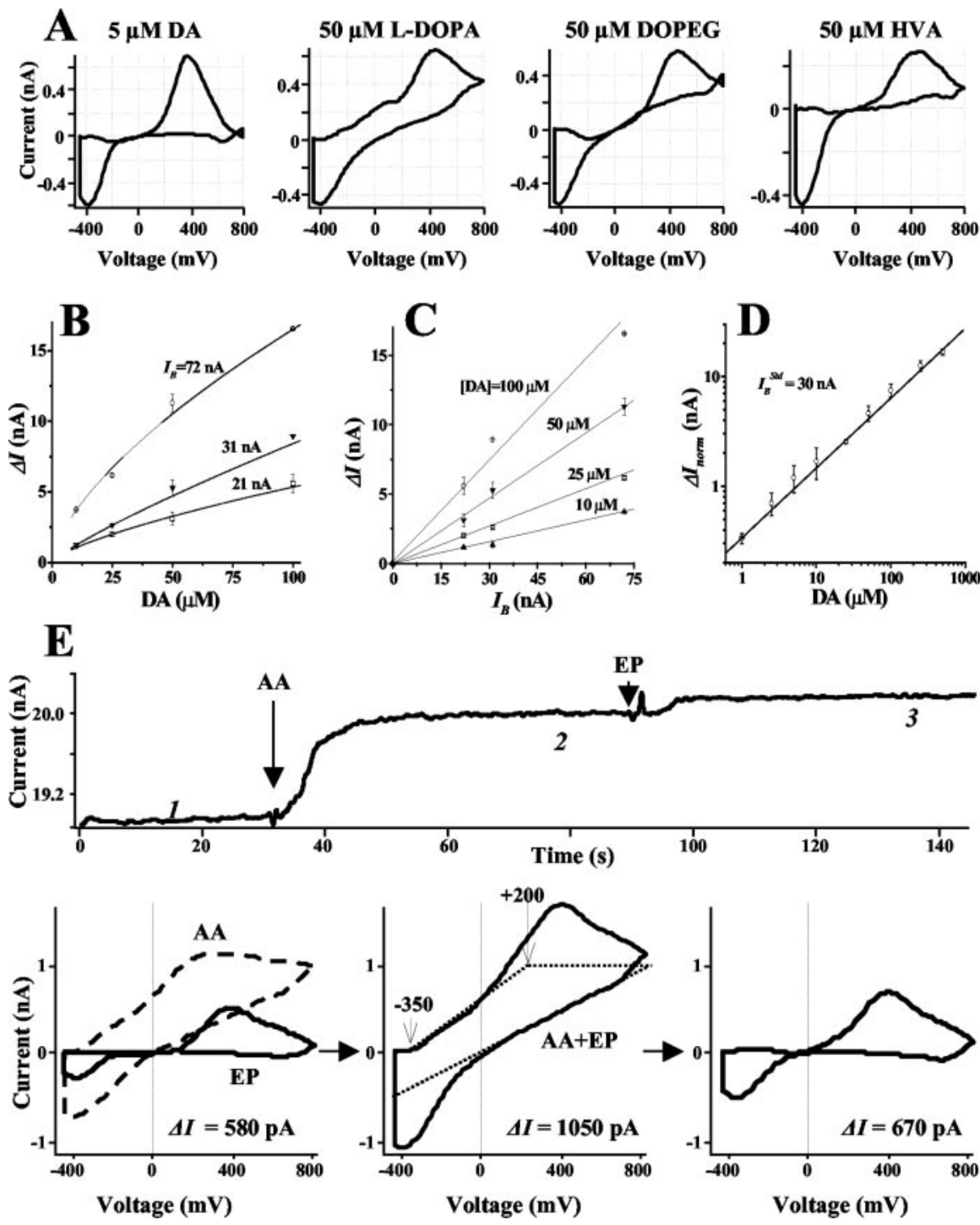

Figure 4. Estimation of cytosolic catecholamine concentrations in CV mode. A, Voltammograms of DA and related compounds. $B$, DA concentration dependencies of $\Delta /$ observed using electrodes with different $I_{B}$. C, Relationship between $I_{B}$ and $\Delta /$ at different DA concentrations. $D$, Calibration curve for DA in a double-logarithmic plot fit by a linear function. $\Delta I_{\text {norm }}$ was calculated using $P_{B}^{t t d}=30 \mathrm{nA}$. Calibration coefficients for DA and other metabolites are listed in Table 1. E, Subtraction of AA contribution from voltammograms. The top panel shows the current sampled at $350 \mathrm{mV}$, in which arrows indicate the additions of $400 \mu \mathrm{m} A A$ and $5 \mu \mathrm{m}$ EP. Bottom, left, Voltammograms of AA alone (dashed line; subtraction voltammogram between points 1 and 2 on the sampled current trace) and EP alone (solid line; subtraction voltammogram between points 2 and 3). Bottom, middle, Voltammogram of the AA and EP mixture (solid line; subtraction voltammogram between points 1 and 3). Dotted lines represent the estimated AA contribution to the voltammogram (see Results). Bottom, right, Original EP voltammogram was approximated as a difference between two traces shown in the bottom middle panel. $\Delta /$ on voltammograms was calculated between currents that corresponded to 0 and $350 \mathrm{mV}$ oxidation potentials.

chromaffin cells, although the effects of these drugs on the cytosolic catecholamine homeostasis have never been measured directly. We used amphetamine, reserpine, pargyline, and L-DOPA to induce perturbations of catecholamine metabolism and monitored changes in the cytosolic catechol and catecholamine pools after drug treatments. Time courses of concentration changes were derived from measurements performed on individual cells incubated for the indicated periods.

\section{Amphetamine}

The changes in cytosolic catecholamine after exposure to amphetamine, methamphetamine, or methylenedioxymethamphetamine (ecstasy) have been a subject of intense conjecture, 

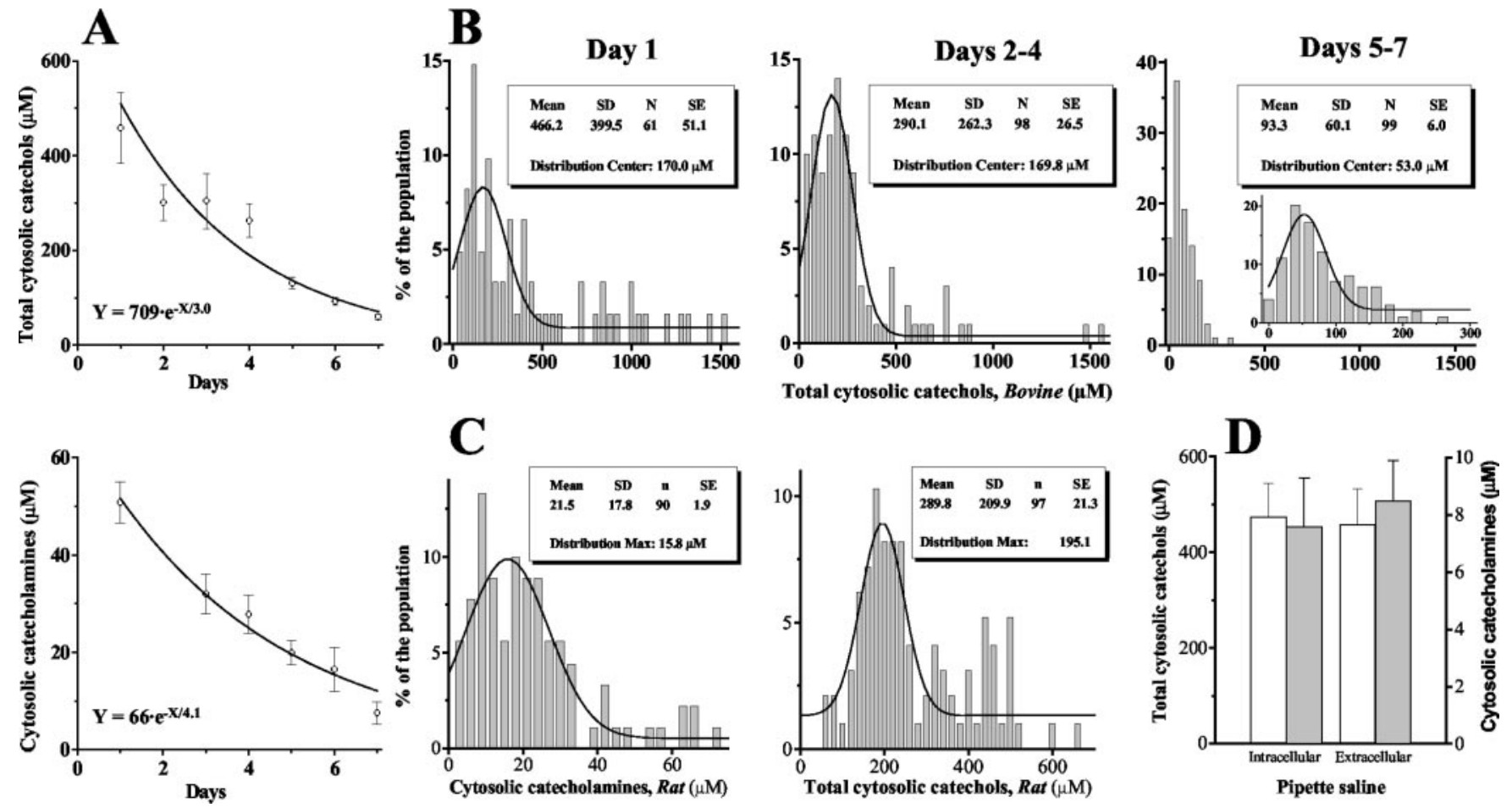

Figure 5. Cytosolic catechols and catecholamines in untreated chromaffin cells. $A$, Cytosolic concentrations of total catechols measured amperometrically (top) and catecholamines measured by CV (bottom) in chromaffin cells at different days in culture. Continuous lines are single exponential fits. B, Distributions of total cytosolic catechol levels in bovine chromaffin cells at day 1 (left), days 2-4 (middle), and days 5-7 (right) in culture (bin size, $40 \mu \mathrm{m}$ ). The inset in the right panel shows the same data points grouped into $20 \mu \mathrm{m}$ bins. C, Distributions of cytosolic catecholamines (left; bin size, $3 \mu \mathrm{m}$ ) and total catechols (right; bin size, $20 \mu \mathrm{m}$ ) in rat chromaffin cells at days $2-4$ after culture. D, Mean concentrations of total cytosolic catechols (white) and catecholamines (gray) recorded using high Ca extracellular (saline A2 or B1) and low Ca intracellular (saline A3 or B2) patch pipette solutions (see Materials and Methods for compositions).

attributable to both the mechanisms by which these drugs act and their neurotoxicity (for review, see Leviel, 2001). The actions of amphetamines include inhibition of mitochondrial monoamine oxidase (MAO) (Davidson et al., 2001), stimulation of catecholamine synthesis (Larsen et al., 2002), and induction of catecholamine reverse transport from the cytosol to the extracellular milieu via dopamine and norepinephrine uptake transporters (dopamine uptake transporter and norepenephrine uptake transporter) (Fischer and Cho, 1979; Sulzer et al., 1995; Sonders et al., 1997; Jones et al., 1998). To explain the magnitude of this response, it has been proposed that cytosolic catecholamines were increased because of their redistribution from secretory vesicles to the cytosol, in part because of the collapse of the vesicular pH gradient (Carlsson et al., 1963; Sulzer and Rayport, 1990; Rudnick and Wall, 1992). In agreement with this hypothesis, amperometric studies of catecholamine-secreting adrenal chromaffin cells and pheochromocytoma PC12 cells demonstrated that quantal size decreased approximately twofold after exposure to amphetamines or other weak bases (Sulzer et al., 1995; Anderson et al., 1998; Mundorf et al., 1999).

Rat chromaffin cell cultures were incubated in saline B1 (see Materials and Methods) containing $50 \mu \mathrm{M}$ amphetamine for 1-80 min at room temperature (RT) before breaking into the cells. Each recording, which usually took 2-4 min, was followed by the next as quickly as possible, and single cell recordings from eight independent experiments were grouped into time bins.

IPE in CV mode revealed an approximately fivefold increase in cytosolic catecholamines during the first 10-15 min of cell incubation with amphetamine (Fig. 6A). After 35-40 min of amphetamine application, the catecholamine concentrations returned to control levels. In contrast, IPE in amperometric mode showed a steady increase of the total catechols in the cytosol during $1.5 \mathrm{hr}$ of amphetamine treatment. By the end of the experiment ( $\sim 90 \mathrm{~min})$, cytosolic catechol content in chromaffin cells was fivefold higher than in controls (Fig. 6B).

\section{Reserpine and tetrabenazine}

The vesicular monoamine transporter (VMAT) blockers, reserpine and tetrabenazine (TBZ), also deplete intracellular catecholamine storage in secretory vesicles (Carlsson et al., 1967; Viveros et al., 1971). Extracellular amperometric recordings have confirmed that these drugs reduce the quantal size of transmitter release (Colliver et al., 2000); however, unlike amphetamine, reserpine and TBZ alone do not induce nonexocytic catecholamine release (Jones et al., 1998).

Using a similar treatment protocol as that for amphetamine, we detected no significant changes in cytosolic catecholamines during $60 \mathrm{~min}$ of chromaffin cell exposure to $1 \mu \mathrm{M}$ reserpine (Fig. $7 A$, left) or $10 \mu \mathrm{M} \mathrm{TBZ}$ (data not shown). Catecholamine concentration in untreated cells and cells treated with reserpine for 20 min was $24.4 \pm 6.9 \mu \mathrm{M}$ (mean $\pm \mathrm{SEM} ; n=9)$ and $20.0 \pm 7.8 \mu \mathrm{M}$ $(n=11)$, respectively. The amperometrically detected total cytosolic catechol levels increased approximately fourfold after reserpine treatment (Fig. $7 A$, right), indicating that catecholamines were rapidly metabolized, presumably to DOPAC and DOPEG, detected by amperometry but not by $\mathrm{CV}$. In agreement with this, application of reserpine on cells pretreated with the MAO inhibitor pargyline $(10 \mu \mathrm{M} ; 30 \mathrm{~min})$ produced an increase in the levels of cytosolic catecholamines (Fig. 7A, left). Total catechol concentrations started to decrease slowly after $\sim 30 \mathrm{~min}$ of reserpine application but were still $>$ twofold higher than in control after 60-80 min (Fig. $7 A$, right). 

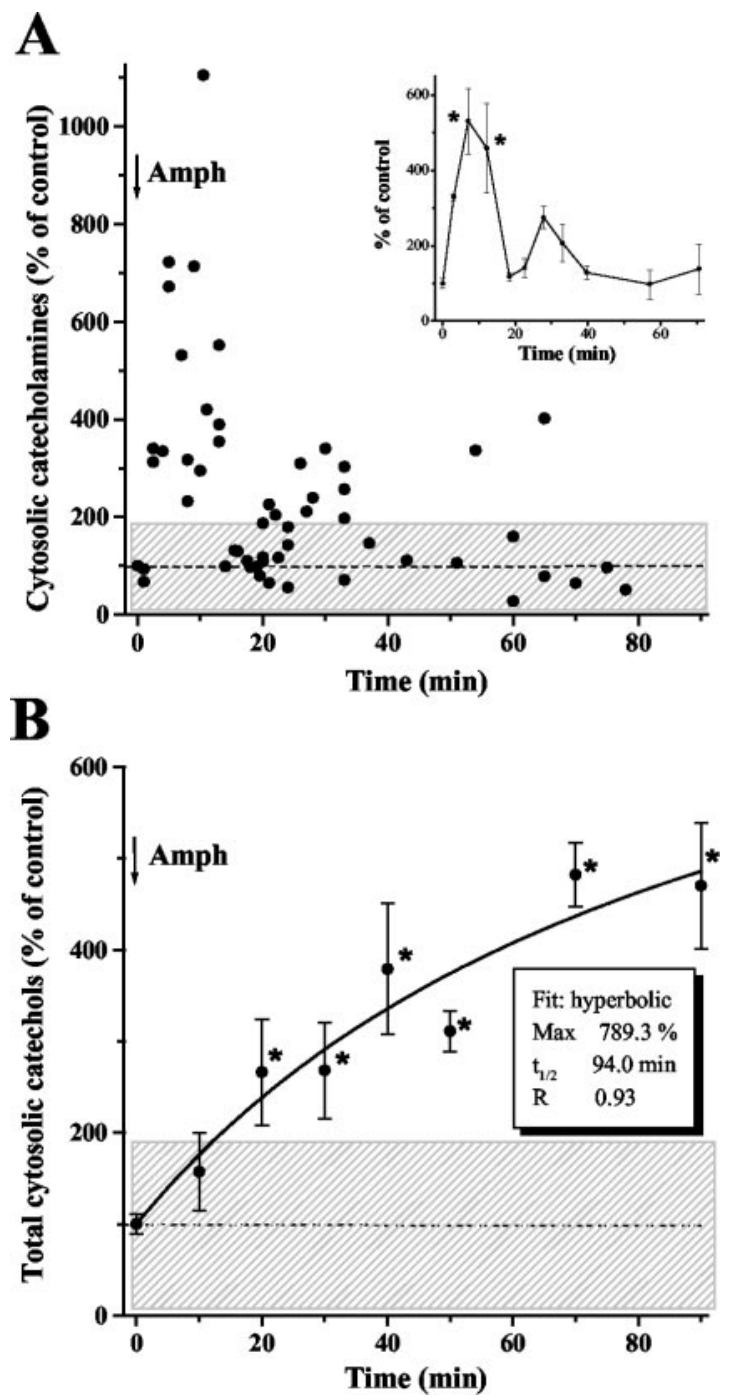

Figure 6. Catecholamine homeostasis in rat chromaffin cells after amphetamine treatment. A, Cytosolic concentrations of catecholamines measured by IPE in CV mode in cells exposed to 50 $\mu \mathrm{M}$ amphetamine (added at time 0 ). Each point represents one cell; inset displays the same data points grouped into time bins (bin size, $5 \mathrm{~min}$ for $0-35$ min and $15 \mathrm{~min}$ for $35-80 \mathrm{~min}$ time points; mean \pm SEM). The data shown are from eight independent experiments. $B$, Total cytosolic catechols measured by IPE in amperometric mode. Data from three independent experiments are shown as mean \pm SEM ( $n=3-6$ for each time point). Shaded areas represent one SD from the mean level of catecholamine or catechol concentrations in untreated chromaffin cells. Asterisks indicate a significant difference from untreated cells ( $p<0.001$; ANOVA test).

\section{$L-D O P A$}

The effect of the catecholamine precursor L-DOPA on cytosolic catecholamines has been extensively studied because of its effects on neurotransmission and potential neurotoxicity from its administration to Parkinson's disease patients (Fahn and Cohen, 1992). L-DOPA increases the quantal size in chromaffin cells by $\sim 70 \%$ (Pothos et al., 2002), suggesting that the availability of dopamine in the cytosol is a rate-limiting step in the process of catecholamine accumulation into vesicles.

Adrenal cells incubated with $100 \mu \mathrm{M}$ L-DOPA for $1 \mathrm{hr}$ displayed twofold to threefold higher cytosolic catecholamine levels (recordings made in the presence of L-DOPA) compared with untreated cells (Fig. 7B, left). After L-DOPA withdrawal from the extracellular media, catecholamine concentrations diminished rapidly and were close to controls after $10-30 \mathrm{~min}(5.6 \pm 1.5 \mu \mathrm{M}$
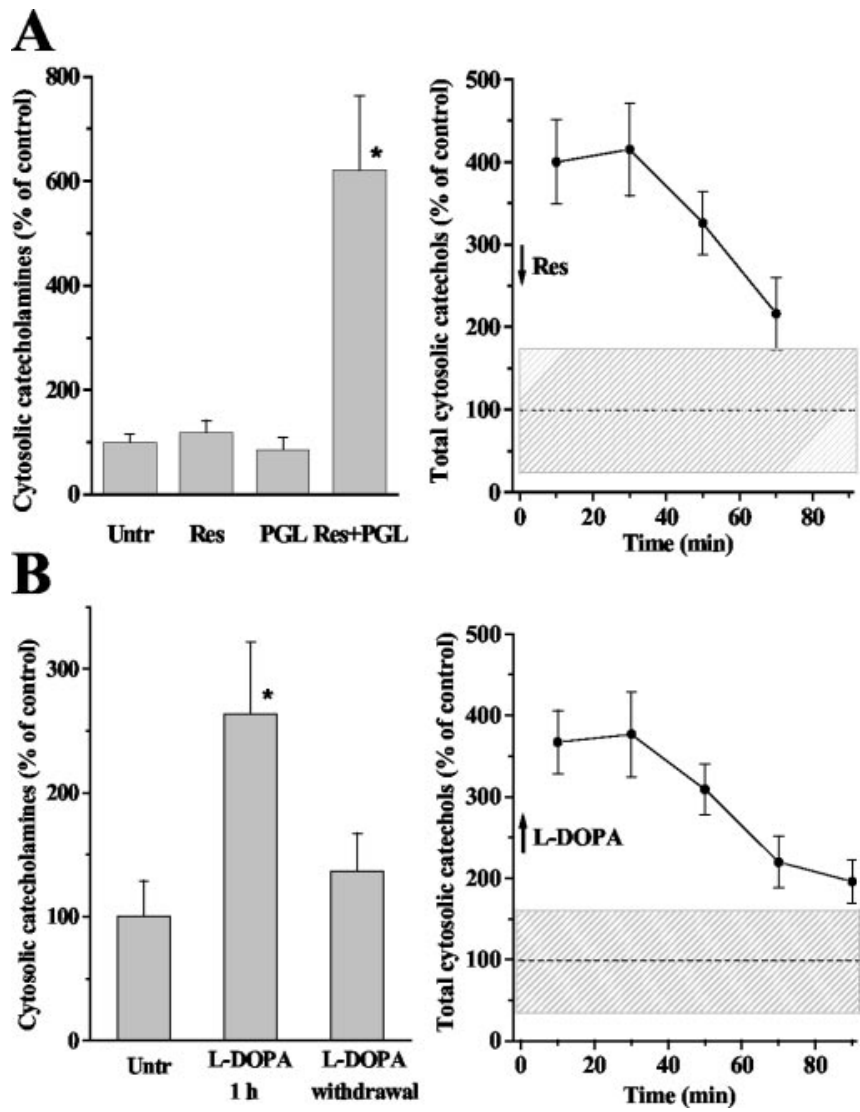

Figure 7. Effects of reserpine, pargyline, and L-DOPA on cytosolic catecholamine homeostasis in rat chromaffin cells. A, Cytosolic catecholamine concentrations measured by IPE in CV mode (left) and total catechols measured by amperometric mode (right) in cells exposed to 1 $\mu \mathrm{m}$ reserpine and $10 \mu \mathrm{m}$ pargyline. Left, Reserpine-treated group represents cells incubated with the drug for 5-60 min. Cells were pretreated with pargyline for $30 \mathrm{~min}$ before measurements or the addition of reserpine, which was added for $15 \mathrm{~min}$. After the treatments $\left(37^{\circ} \mathrm{C} ; 7 \%\right.$ $\left.\mathrm{CO}_{2}\right)$, the media were replaced with saline $\mathrm{B} 1$ containing the same drugs. Measurements were performed at RT during 60 min after the treatments. The following is the number of points in cells: untreated, $n=22$; reserpine-treated, $n=21$; pargyline-treated, $n=16$; pargyline and reserpine-treated, $n=28$. Right, Reserpine was added at time 0 . Combined data from three experiments are grouped into 20 min time bins with $n=13-24$ for different time point. $B$, Cytosolic concentrations of catecholamines (left) and total catechols (right) after cell exposure to $100 \mu \mathrm{m}$ L-DOPA. Left, Middle bar represents cytosolic catecholamine concentration in chromaffin cells incubated with L-DOPA for 1-1.5 hr; recordings were made in the presence of L-DOPA. The right bar represents the level of catecholamines in cells preincubated with L-DOPA for $1 \mathrm{hr}$ and washed twice with L-DOPA-free medium (10-60 min after L-DOPA withdrawal). The following is the number of points in cells: untreated, $n=25$; L-DOPA-treated, 24; cells pretreated with L-DOPA after L-DOPA withdrawal, 17. Right, Time course of changes in the level of total cytosolic catechols after L-DOPA withdrawal. Data from four independent experiments are grouped into 20 min time bins ( $n=14-24$ for different time points). Data shown as mean \pm SEM. Shaded areas represent one SD from the mean catechol concentrations in untreated chromaffin cells. All time points in the right panels and those that have asterisks in the left panels are significantly different from untreated cells ( $p<0.001$; ANOVA test).

for control, $n=25 ; 7.1 \pm 1.3 \mu \mathrm{M}$ for L-DOPA, $n=6$ ). Total cytosolic catechols were approximately fourfold elevated in cells preincubated with L-DOPA and remained approximately twofold higher than control after $\sim 90 \mathrm{~min}$ of cell incubation in L-DOPA-free media (Fig. $7 B$, right).

\section{Discussion}

By combining patch amperometry and CV, we have developed intracellular patch electrochemistry, an approach that directly measures cytosolic oxidizable metabolites. Using this technique, we studied the regulation of catecholamine metabolism in the 
cytosol of cultured rat and bovine adrenal chromaffin cells under resting conditions and after treatment with a variety of agents that have been previously suggested to redistribute intracellular catecholamine pools.

\section{Cytosolic catecholamine homeostasis}

Although there are substantial differences between catecholamine exocytosis in chromaffin cells and neurons, they share many of the features of catecholamine intracellular homeostasis, including the presence of key enzymes and transporters (Bader et al., 2002; Tischler, 2002). Catecholamines are synthesized in the cytosol from tyrosine, which is converted to L-DOPA by tyrosine hydroxylase $(\mathrm{TH})$, the rate-limiting enzyme in catecholamine synthesis, and then to DA by aromatic L-amino acid decarboxylase. After VMAT-mediated accumulation into secretory vesicles, in chromaffin cells, DA is metabolized to NE by dopamine $\beta$-hydroxylase, which requires AA as a cofactor. NE can return to the cytosol, and, in some cells, is converted to EP that is again taken up into the vesicles. A chromaffin cell may thus contain DA, NE, and EP in the cytosol and primarily NE or EP in the granules (Cooper et al., 1991). Negative feedback regulation of TH by DA, and catecholamine degradation by the mitochondrial $\mathrm{MAO}$, are the two major mechanisms that maintain catecholamine concentrations in the cytosol at a low level. Measurements of cytosolic pool of catecholamines in GDN of the pond snail showed that $\geq 98 \%$ of intracellular catecholamine is bound (presumably in vesicles) and not accessible to the cytoplasm (Chien et al., 1990).

Using IPE in amperometric mode, we found that in chromaffin cells, the cumulative concentration of cytosolic oxidizable metabolites, including the catecholamines DA, NE, and EP, their precursor L-DOPA and the degradation products DOPEG, DOPAC, HVA, and AA ranged from 50 to $500 \mu \mathrm{M}$ (Fig. 5). IPE in CV mode, used to preferentially measure the catecholamines DA, $\mathrm{NE}$, and EP, showed that cytosolic levels of these metabolites were 2-50 $\mu \mathrm{M}$ (Fig. $5 C$, left), which was $\sim 10 \%$ of the total cytosolic catechol concentration. To date, this provides the only available data on the absolute concentrations of catechols in the cytosol of mammalian cells.

On the first day after plating, catecholamine and total catechol levels were $30-40 \%$ higher than in the subsequent $3 \mathrm{~d}$ (Fig. $5 \mathrm{~A}$ ), accompanied by low exocytic activity of chromaffin cells during the first day in culture (R. Staal, unpublished data). These data implicate that culture preparation induced distortions of normal intracellular catecholamine homeostasis, which led to increased cytosolic levels and decreased vesicular catecholamine levels.

Unexpectedly, reserpine and TBZ, inhibitors of catecholamine uptake into the vesicles, had little effect on the cytosolic concentrations of catecholamines measured by CV (Fig. 7A), confirming the data from snail neurons (Chien et al., 1990). In the presence of the MAO inhibitor pargyline, reserpine induced an approximately sixfold increase of catecholamine levels in the cytosol, suggesting that catecholamines redistributed from secretory vesicles were rapidly degraded to DOPAC and DOPEG. Consistent with this mechanism, the level of total catechols greatly increased in the presence of reserpine (Fig. 7A). Surprisingly, pargyline alone did not induce any detectable catecholamine alterations, presumably because of the exocytic quiescence of chromaffin cells in culture and a slow rate of catecholamine turnover in the cytosol.

Amphetamine treatment caused a substantial but short-lived increase of cytosolic catecholamines, closely following the time course of amphetamine-mediated catecholamine release ob- served on neuronal preparations (Jones et al., 1998; Schmitz et al., 2001). These data provide direct evidence for the displacement of vesicular catecholamine into the cytosol by psychostimulants proposed previously (Carlsson et al., 1963; Sulzer and Rayport, 1990). A slow accumulation of amperometrically detected catechols during the following 90 min (Fig. 6) was consistent with the formation of catecholamine degradation products, which was delayed because of partial inhibition of MAO (Miller et al., 1980; Davidson et al., 2001).

Chromaffin cells exposed to $100 \mu \mathrm{M}$ L-DOPA showed a twofold to threefold increase in the concentration of cytosolic catecholamines (Fig. $7 B$ ), in accordance with an increased quantal size in chromaffin cells incubated with L-DOPA (Pothos et al., 2002) and confirming the equilibrium between cytosolic and vesicular catecholamine levels (Njus et al., 1986; Johnson, 1988). Additionally, L-DOPA treatment induced a substantial enhancement of catecholamine catabolism, which led to a fourfold to fivefold elevation of the total catechol levels, in agreement with previous reports (Ahlskog et al., 1996; Fisher et al., 2000). After L-DOPA withdrawal, catecholamines returned to control levels after $\leq 10 \mathrm{~min}$, whereas total catechols remained approximately twofold increased even after $1.5 \mathrm{hr}$ of incubation in L-DOPA-free saline. This difference in the rate of catecholamine and catechol clearance from the cytosol, together with reserpine and amphetamine data, suggest that DOPAC transport from the cytosol to the extracellular milieu is the rate-limiting step in cytosolic catecholamine catabolism.

Together, our data indicate that in chromaffin cells, cellular homeostasis maintains cytosolic catecholamines at a stable low level under a wide range of changes in VMAT, MAO, and $\mathrm{TH}$ activities. Interventions expected to increase cytosolic catecholamine concentration have relatively short-lasting effects. Excessive amounts of DA, EP, and NE are rapidly converted to other catecholamine derivatives, such as DOPAC and DOPEG. In contrast, elevated levels of catecholamine degradation products can reside in the cytosol for hours after treatment and may contribute to the quinone species formation and cellular oxyradical damage.

\section{Methodological concerns}

Using CV, we detected the presence of substantial amounts of cytosolic metabolites other than catechols in 50\% of chromaffin cells. In part, this can be explained by a higher susceptibility of CFEs in the CV mode to various sources of experimental noise, such as changes in pressure and salt composition after the patch rupture. During patch formation, before intracellular metabolites were able to diffuse into the patch pipette, these noises were also observed in the $\mathrm{CV}$ but not in the amperometric mode of IPE. Hence, a portion, if not most, of the noncatechol CV currents might be attributable to processes other than the oxidation of cytosolic molecules and were not detected by amperometry. However, if the real cytosolic concentrations of catechols were lower than estimated by amperometry, the relative changes of the total catechol pools induced by different drugs were greater than discussed above.

Another concern is that a portion of the oxidation current measured by IPE may represent vesicular rather than the cytosolic pool of catecholamines. In this case, catechol levels will be overestimated, especially in CV mode, which does not have the time resolution to detect and subsequently subtract catecholamines released from vesicles (Fig. 1C, arrowheads). However, our data with VMAT inhibitors argue against this possibility because a depletion of vesicular catecholamine stores did not affect cytosolic catecholamine concentrations measured by IPE 
in $\mathrm{CV}$ mode (Fig. 7A). In addition, the kinetics of amphetamineinduced changes in catecholamine level (Fig. 6A) can only be explained by the effects of this drug on the cytosolic but not on the vesicular pool of the hormone. Finally, previous studies on isolated chromaffin granules showed a low permeability of the vesicular membrane both to ions and the amine over a $24 \mathrm{hr}$ period (Maron et al., 1983), implying that there should have been no catecholamine leakage from the vesicles during our recordings.

Several other factors can also lead to an underestimation or overestimation of the true cytosolic catechol concentrations measured by IPE. Overestimation of the cytosolic volume and the possible loss of molecules because of their diffusion into the shaft of the patch pipette (see Materials and Methods) would underestimate cytosolic metabolite levels. The assumption that DA represented most of the cytosolic catecholamines (because NE is synthesized inside the vesicles) may lead to an underestimate of catecholamine levels measured by $\mathrm{CV}$, because DA yielded a higher CV oxidation current than NE and EP (Table 1). In addition, catechols can donate either two or four electrons per molecule under different conditions (Ciolkowski et al., 1994), therefore, introducing another uncertainty in our calculations (see Materials and Methods). It is difficult to ascertain whether any of these factors prevailed in our experiments or whether they negated each other, and the absolute concentrations of free cytosolic metabolites may be a few-fold higher or lower than estimated by IPE. Despite these concerns, a relative comparison of metabolite levels in cells treated with various agents is often of greater interest, and the suitability of IPE for this kind of measurement is supported by our data.

Overall, IPE provides a means to directly observe processes only hypothesized previously to be regulated by cytosolic catechol pools. Given the ongoing advances in electrochemical detection that now provide measurement of a broad variety of compounds, IPE may help to elucidate the regulation of diverse cytosolic metabolites, including classical neurotransmitters, nitric oxide (Villeneuve et al., 1998), reactive oxygen species (Navera et al., 1991; Privat et al., 1999), and ascorbate (Gonon et al., 1981; Cahill and Wightman, 1995). It may also prove useful for studies of transmembrane transport of metabolic compounds that can be coupled with the measurements of associated ionic currents.

\section{References}

Ahlskog JE, Uitti RJ, Low PA, Tyce GM, O’Brien JF, Nickander KK (1996) Levodopa and deprenyl treatment effects on peripheral indices of oxidant stress in Parkinson's disease. Neurology 46:796-801.

Albillos A, Dernick G, Hostmann H, Almers W, Alvarez de Toledo G, Lindau M (1997) The exocytic event in chromaffin cells revealed by patch amperometry. Nature 389:509-512.

Anderson BB, Chen G, Gutman DA, Ewing AG (1998) Dopamine levels of two classes of vesicles are differentially depleted by amphetamine. Brain Res 788:294-301.

Bader MF, Holz RW, Kumakura K, Vitale N (2002) Exocytosis: the chromaffin cell as a model system. Ann NY Acad Sci 971:178-183.

Baur JE, Kristensen EW, May LJ, Wiedemann DJ, Wightman RM (1988) Fast-scan voltammetry of biogenic amines. Anal Chem 60:1268-1272.

Berg HC (1983) Random walks in biology, pp 131-133. Princeton, NJ: Princeton UP.

Bruns D, Jahn R (1995) Real-time measurement of transmitter release from single synaptic vesicles. Nature 377:62-65.

Cahill PS, Wightman RM (1995) Simultaneous amperometric measurement of ascorbate and catecholamine secretion from individual bovine adrenal medullary cells. Anal Chem 67:2599-2605.

Carlsson A, Hillarp N, Waldeck B (1963) Analysis of the $\mathrm{Mg}^{2+}$-ATP depen- dent storage mechanism in the amine granules of the adrenal medulla. Acta Physiol Scand 59:215.

Carlsson A, Fuxe K, Hokfelt T (1967) Effect of desmethylimipramine, protriptyline and $(+)$-amphetamine on fluorescence of central adrenergic neurons of rats pretreated with alpha-methyl-DOPA and tetrabenazine or reserpine. Eur J Pharmacol 2:196-201.

Chen G, Gavin PF, Luo G, Ewing AG (1995) Observation and quantitation of exocytosis from the cell body of a fully developed neuron in Planorbis corneus. J Neurosci 15:7747-7755.

Chien JB, Wallingford RA, Ewing AG (1990) Estimation of free dopamine in the cytoplasm of the giant dopamine cell of Planorbis corneus by voltammetry and capillary electrophoresis. J Neurochem 54:633-638.

Chow RH, von Ruden L (1995) Electrochemical detection of secretion from single cells. In: Single-channel recording (Sakmann B, Neher E, eds), pp 245-276. New York: Plenum.

Ciolkowski EL, Maness KM, Cahill PS, Wightman RM, Evans DH, Fosset B, Amatore C (1994) Disproportionation during electrooxidation of catecholamines at carbon-fiber microelectrodes. Anal Chem 66:3611-3617.

Colliver TL, Pyott SJ, Achalabun M, Ewing AG (2000) VMAT-mediated changes in quantal size and vesicular volume. J Neurosci 20:5276-5282.

Conway KA, Rochet JC, Bieganski RM, Lansbury Jr PT (2001) Kinetic stabilization of the alpha-synuclein protofibril by a dopamine-alphasynuclein adduct. Science 294:1346-1349.

Cooper JR, Bloom FE, Roth RH (1991) The biochemical basis of neuropharmacology. New York: Oxford UP.

Davidson C, Gow AJ, Lee TH, Ellinwood EH (2001) Methamphetamine neurotoxicity: necrotic and apoptotic mechanisms and relevance to human abuse and treatment. Brain Res Brain Res Rev 36:1-22.

Fahn S, Cohen G (1992) The oxidant stress hypothesis in Parkinson's disease: evidence supporting it. Ann Neurol 32:804-812.

Fischer JF, Cho AK (1979) Chemical release of dopamine from striatal homogenates: evidence for an exchange diffusion model. J Pharmacol Exp Ther 208:203-209.

Fisher A, Biggs CS, Eradiri O, Starr MS (2000) Dual effects of L-3, 4-dihydroxyphenylalanine on aromatic L-amino acid decarboxylase, dopamine release and motor stimulation in the reserpine-treated rat: evidence that behaviour is dopamine independent. Neuroscience 95:97-111.

Gonon F, Cespuglio R, Ponchon JL, Buda M, Jouvet M, Adams RN, Pujol JF (1978) In vivo continuous electrochemical determination of dopamine release in rat neostriatum. C R Acad Sci Hebd Seances Acad Sci D 286:1203-1206.

Gonon F, Buda M, Cespuglio R, Jouvet M, Pujol JF (1981) Voltammetry in the striatum of chronic freely moving rats: detection of catechols and ascorbic acid. Brain Res 223:69-80.

Ingebretsen OC, Terland O, Flatmark T (1980) Subcellular distribution of ascorbate in bovine adrenal medulla. Evidence for accumulation in chromaffin granules against a concentration gradient. Biochim Biophys Acta 628:182-189.

Jaffe EH, Marty A, Schulte A, Chow RH (1998) Extrasynaptic vesicular transmitter release from the somata of substantia nigra neurons in rat midbrain slices. J Neurosci 18:3548-3553.

Johnson RG (1988) Accumulation of biological amines into chromaffin granules: a model for hormone and neurotransmitter transport. Physiol Rev 68:232-307.

Jones SR, Gaindetdinov RR, Wightman RM, Caron MG (1998) Mechanisms of amphetamine action revealed in mice lacking the dopamine transporter. J Neurosci 18:1979-1986.

Kissinger PT, Hart JB, Adams RN (1973) Voltammetry in brain tissue-a new neurophysiological measurement. Brain Res 55:209-213.

Larsen KE, Fon EA, Hastings TG, Edwards RH, Sulzer D (2002) Methamphetamine-induced degeneration of dopaminergic neurons involves autophagy and upregulation of dopamine synthesis. J Neurosci 22:8951-8960.

Leviel V (2001) The reverse transport of DA, what physiological significance? Neurochem Int 38:83-106.

Levine M, Morita K, Pollard H (1985) Enhancement of norepinephrine biosynthesis by ascorbic acid in cultured bovine chromaffin cells. J Biol Chem 260:12942-12947.

Lindau M, Neher E (1988) Patch-clamp techniques for time-resolved capacitance measurements in single cells. Pflügers Arch 411:137-146.

Lotharius J, O’Malley KL (2000) The parkinsonism-inducing drug 
1-methyl-4-phenylpyridinium triggers intracellular dopamine oxidation. A novel mechanism of toxicity. J Biol Chem 275:38581-38588.

Maron R, Stern Y, Kanner BI, Schuldiner S (1983) Functional asymmetry of the amine transporter from chromaffin granules. J Biol Chem 258:11476-11481.

Miller HH, Shore PA, Clarke DE (1980) In vivo monoamine oxidase inhibition by d-amphetamine. Biochem Pharmacol 29:1347-1354.

Mundorf ML, Hochstetler SE, Wightman RM (1999) Amine weak bases disrupt vesicular storage and promote exocytosis in chromaffin cells. J Neurochem 73:2397-2405.

Navera EN, Sode K, Tamiya E, Karube I (1991) Development of acetylcholine sensor using carbon fiber (amperometric determination). Biosens Bioelectron 6:675-680.

Nicholson C (1999) Diffusion of ions and macromolecules in brain tissue. In: Monitoring molecules in neuroscience (Rollema $\mathrm{H}$, Abercrombie $\mathrm{E}$, Sulzer D, Zackheim J, eds), pp 71-73. Newark, NJ: Rutgers.

Njus D, Kelley PM, Harnadek GJ (1986) Bioenergetics of secretory vesicles. Biochim Biophys Acta 853:237-265.

Olefirowicz TM, Ewing AG (1990) Dopamine concentration in the cytoplasmic compartment of single neurons determined by capillary electrophoresis. J Neurosci Methods 34:11-15.

Parsons TD, Coorssen JR, Horstmann H, Almers W (1995) Docked granules, the exocytic burst, and the need for ATP hydrolysis in endocrine cells. Neuron 15:1085-1096.

Pihel K, Walker QD, Wightman RM (1996) Overoxidized polypyrrole coated carbon fiber microelectrodes for dopamine measurements with fast scan cyclic voltammetry. Anal Chem 68:2084-2089.

Ponchon JL, Cespuglio R, Gonon F, Jouvet M, Pujol JF (1979) Normal pulse polarography with carbon fiber electrodes for in vitro and in vivo determination of catecholamines. Anal Chem 51:1483-1486.

Pothos E, Davila V, Sulzer D (1998) Presynaptic recording of quanta from midbrain dopamine neurons and modulation of the quantal size. J Neurosci 18:4106-4118.

Pothos EN, Mosharov E, Liu KP, Setlik W, Haburcak M, Baldini G, Gershon MD, Tamir H, Sulzer D (2002) Stimulation-dependent regulation of the $\mathrm{pH}$, volume and quantal size of bovine and rodent secretory vesicles. J Physiol (Lond) 542:453-476.

Privat C, Stepien O, David-Dufilho M, Brunet A, Bedioui F, Marche P, Devynck J, Devynck MA (1999) Superoxide release from interleukin1B-stimulated human vascular cells: in situ electrochemical measurement. Free Radic Biol Med 27:554-559.

Pusch M, Neher E (1988) Rates of diffusional exchange between small cells and a measuring patch pipette. Pflügers Arch 411:204-211.

Rudnick G, Wall SC (1992) The molecular mechanism of "ecstasy" [3, 4-methylenedioxymethamphetamine (MDMA)]: serotonin transporters are targets for MDMA-induced serotonin release. Proc Natl Acad Sci USA 89:1817-1821.

Schmitz Y, Lee CJ, Schmauss C, Gonon F, Sulzer D (2001) Amphetamine distorts synaptic dopamine overflow: effects on D2 autoreceptors, transporters, and synaptic vesicle stores. J Neurosci 21:5916-5924.
Shastry BS (2001) Parkinson disease: etiology, pathogenesis and future of gene therapy. Neurosci Res 41:5-12.

Shen XM, Xia B, Wrona MZ, Dryhurst G (1996) Synthesis, redox properties, in vivo formation, and neurobehavioral effects of $\mathrm{N}$-acetylcysteinyl conjugates of dopamine: possible metabolites of relevance to Parkinson's disease. Chem Res Toxicol 9:1117-1126.

Sonders MS, Zhu SJ, Zahniser NR, Kavanaugh MP, Amara SG (1997) Multiple ionic conductances of the human dopamine transporter: the actions of dopamine and psychostimulants. J Neurosci 17:960-974

Spencer JP, Whiteman M, Jenner P, Halliwell B (2002) 5-s-Cysteinylconjugates of catecholamines induce cell damage, extensive DNA base modification and increases in caspase- 3 activity in neurons. J Neurochem $81: 122-129$.

Stokes AH, Hastings TG, Vrana KE (1999) Cytotoxic and genotoxic potential of dopamine. J Neurosci Res 55:659-665.

Sulzer D, Pothos EN (2000) Presynaptic mechanisms that regulate quantal size. Rev Neurosci 11:159-212.

Sulzer D, Rayport S (1990) Amphetamine and other psychostimulants reduce $\mathrm{pH}$ gradients in midbrain dopaminergic neurons and chromaffin granules: a mechanism of action. Neuron 5:797-808.

Sulzer D, Chen T, Lau Y, Kristensen H, Rayport S, Ewing A (1995) Amphetamine redistributes dopamine from synaptic vesicles to the cytosol and promotes reverse transport. J Neurosci 15:4102-4108.

Sulzer D, Bogulavsky J, Larsen KE, Karatekin E, Kleinman M, Turro N, Krantz D, Edwards R, Greene LA, Zecca L (2000) Neuromelanin biosynthesis is driven by excess cytosolic catecholamines not accumulated by synaptic vesicles. Proc Natl Acad Sci USA 97:11869-11874.

Thompson RE, Lindau M, Webb WW (2001) Robust, high-resolution, whole cell patch-clamp capacitance measurements using square wave stimulation. Biophys J 81:937-948.

Tischler AS (2002) Chromaffin cells as models of endocrine cells and neurons. Ann NY Acad Sci 971:366-370.

Villeneuve N, Bedioui F, Voituriez K, Avaro S, Vilaine JP (1998) Electrochemical detection of nitric oxide production in perfused pig coronary artery: comparison of the performances of two electrochemical sensors. J Pharmacol Toxicol Methods 40:95-100.

Viveros OH, Arqueros L, Kirshner N (1971) Mechanism of secretion from the adrenal medulla. VI. Effect of reserpine on the dopamine-hydroxylase and catecholamine content and on the buoyant density of adrenal storage vesicles. Mol Pharmacol 7:434-443.

Wiedemann DJ, Basse-Tomusk A, Wilson RL, Rebec GV, Wightman RM (1990) Interference by DOPAC and ascorbate during attempts to measure drug-induced changes in neostriatal dopamine with Nafion-coated, carbon-fiber electrodes. J Neurosci Methods 35:9-18.

Wightman RM, Jankowski JA, Kennedy RT, Kawagoe KT, Schroeder TJ, Leszczyszyn DJ, Near JA, Diliberto Jr EJ, Viveros OH (1991) Temporally resolved catecholamine spikes correspond to single vesicle release from individual chromaffin cells. Proc Natl Acad Sci USA 88:10754-10758. 